\title{
"Clinical Profile of High and Pathological Myopia: A Study in Bangabandhu Sheikh Mujib Medical University (BSMMU), Dhaka, Bangladesh"
}

\author{
Zahida Jabbar $^{1 *}$, Mohammad Nizamul Hossain Sowdagar ${ }^{2}$, Mehjabin Haque ${ }^{3}$, Sonia Ahsan ${ }^{4}$, Nusrat Jahan Runa ${ }^{5}$, Zafar \\ Khaled $^{6}$

\footnotetext{
${ }^{1}$ Consultant, Department of Ophthalmology, Bangabandhu Sheikh Mujib Medical University (BSMMU), Dhaka, Bangladesh

${ }^{2}$ Lt. Col. Army medical Core, Dhaka, Bangladesh

${ }^{3}$ Assistant Professor, Department of Ophthalmology, Bangabandhu Sheikh Mujib Medical University (BSMMU), Dhaka, Bangladesh

${ }^{4}$ Consultant, Department of Ophthalmology, Bangabandhu Sheikh Mujib Medical University (BSMMU), Dhaka, Bangladesh

${ }^{5}$ Assistant Professor, Department of Pathology, Dhaka Central International Medical College, Dhaka, Bangladesh

${ }^{6}$ Chairman, Department of Ophthalmology, Bangabandhu Sheikh Mujib Medical University (BSMMU), Dhaka, Bangladesh
}

| Received: 21.04.2020 | Accepted: 09.05.2020 | Published: 17.05.2020

*Corresponding author: Zahida Jabbar

Abstract

Original Research Article

Introduction: Myopia is an important cause of visual disability throughout the world, and in its higher forms, it is also an important cause of blindness. Myopia is one of the most common causes of visual disability of the eye and important cause of defective vision affecting the younger age groups. Objective: In our study, efforts are made to find out incidence, prevalence, various symptoms and signs of high and pathological myopia in different age groups and their visual acuity. Methods: This is a prospective study of the Demographic pattern, Posterior segment changes and its effect on visual acuity in patients with High and Pathological Myopia in 100 cases attending in Ophthalmology Department, Bangabandhu Sheikh Mujib Medical University (BSMMU), Dhaka, Bangladesh for a period from June 2015 to May 2017. The patients with refractive error of $\geq-6 \mathrm{D}$ and with normal corneal curvature are included in the study. Patients with refractive error of <-6D, with index myopia, with abnormal corneal curvature (Curvature Myopia) are excluded from the study. Results: Out of these 100 cases, 196 eyes were diagnosed to have high myopia (>-6.00 Dsph) and pathological Myopia (>-15 D sph) after thorough clinical examination \& investigations. Conclusion: High myopic and pathological myopic patients tend to suffer from compromised quality of life owing to various influences from functional, psychological, cosmetic, and financialfactors. So these patients should be given special care, and all modalities of treatment were instituted to improve the quality of life and vision.

Keywords: High myopia, fundal changes, quality of life, geographic variation.

Copyright @ 2020: This is an open-access article distributed under the terms of the Creative Commons Attribution license which permits unrestricted use, distribution, and reproduction in any medium for non-commercial use (NonCommercial, or CC-BY-NC) provided the original author and source are credited.

\section{INTRODUCTION}

Myopia is an important cause of visual disability throughout the world, and in its higher forms, it is also an important cause of blindness. The expense of its optical correction and complications made it a serious social \& economic problem. Myopia has an early onset and associated with several peripheral degenerations and causing defective vision. The prevalence of high \& pathological myopia varies from country to country and from race to race with marked increase in Asia. The parameters for increased prevalence include a higher level of education of children and parents, a change in the lifestyle including less time spent outdoors and more time spent indoors during childhood and adolescence, the urban region of habitation, and higher socioeconomic background of the parents. Pathological myopia is a hereditary disease and transmitted as an autosomal recessive trait. It can be associated with other ocular \& systemic diseases. Environmental factors, prenatal \& neonatal diseases (prematurity, syphilis, Toxoplasmosis of the infant \& maternal toxaemia, alcoholism \& rubella) are associated with pathologic myopia. Streneous physical labour and repeated valsalva manuvores can have the effect of increased intraocular pressure and scleral wall stress. The precise manner in which excessive axial elongation occurs in high \& pathologic myopias remains unknown. The exact relationship between this elongation and the complications of the disease such as chorioretinal degeneration, retinal detachment and glaucoma remain unknown. This finding correlates with the study of Curtin BJ and Karlin DB in 1971 that showed that 
lacquer cracks are usually seen in eyes with axial diameter of more than $26.50 \mathrm{~mm}$ in high myopia.

\begin{tabular}{|c|c|c|c|c|}
\hline $\begin{array}{r}\text { SI. } \\
\text { No. }\end{array}$ & Study & Year & Percentage & $\begin{array}{c}\text { The axial length of } \\
\text { the eye }\end{array}$ \\
\hline & $\begin{array}{c}\text { Curtin BJ, } \\
\text { Karlin DB }\end{array}$ & 1971 & $4.3 \%$ & $>26.5 \mathrm{~mm}$ \\
\hline 2. & Present study & $\begin{array}{c}2015 \text { to } \\
2017\end{array}$ & $5.6 \%$ & $>26.5 \mathrm{~mm}$ \\
\hline
\end{tabular}

\section{OBJECTIVE}

In our study, efforts are made to find out incidence, prevalence, various symptoms and signs of high and pathological myopia in different age groups and their visual acuity.

\section{Materials And Methods}

The study includes 100 cases of myopia $(\geq-$ 6D), who attended the Outpatient in the department of Ophthalmology, Bangabandhu Sheikh Mujib Medical University (BSMMU), Dhaka, Bangladesh for a period from June 2015 to May 2017. The patients with refractive error of $\geq-6 \mathrm{D}$ and with normal corneal curvature are included in the study. Patients with refractive error of <-6D, with index myopia, with abnormal corneal curvature (Curvature myopia) are excluded from the study. A detailed clinical history and examination of the patient was done with appropriate investigations like slit-lamp examination for anterior segment changes, recording of visual acuity, refraction with. Atropine $1 \%$ for children, homatropine or phenylephrine or tropicamide eye drops for adults, Post mydriatic test, direct ophthalmoscopy, Indirect ophthalmoscopy: for evaluation of posterior segment and peripheral retinal changes, IOP measurement with Goldmann applanation tonometer, keratometry, B-scan, A-scan biometry, gonioscopy and visual fields in all cases. All data analysis windows SPSS version 19.00.

\section{ObSeRVATIONS AND Results}

A total of 100 new cases were seen in the outpatient department of ophthalmology, Bangabandhu Sheikh Mujib Medical University (BSMMU), Dhaka, Bangladesh for a period from June 2015 to May 2017. Out of these 100 cases, 196 eyes were diagnosed to have high (>-6.00 Dsph) and pathological myopia and were taken into the study and were followed for two years. In this study, the highest number of high and pathological myopia cases was noted in the age group of 11-30 years [Figure-1].

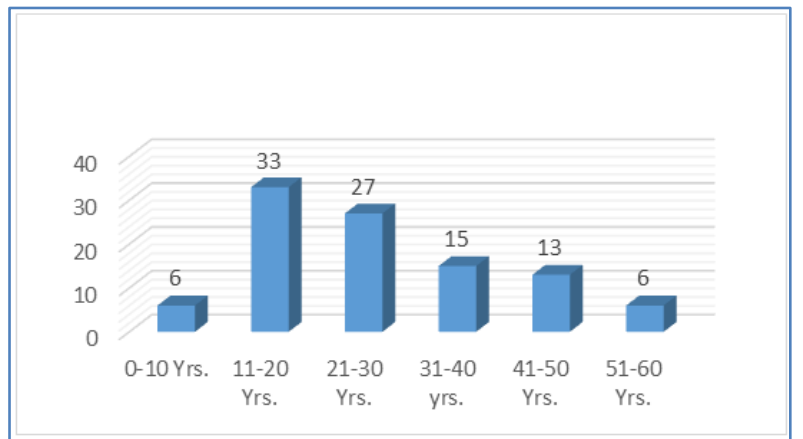

Fig-1: Age Incidence

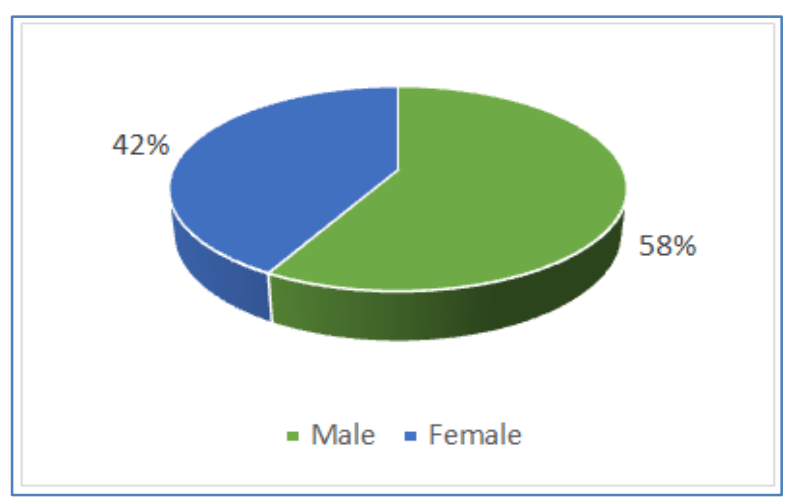

Fig-2: Sex distribution of Myopia patients.

In this study, the incidence of myopia was slightly higher in males accounting to $58 \%$ whereas females accounting to $42 \%$ [Figure-2]. Out of a hundred patients examined, $96 \%$ showed high bilateral myopia (>-6.00 Dsph) and 4\% showed unilateral high myopia (>-6.00 Dsph).

Table-1: Axial Length of the Eye Ball ( $N=100)$

\begin{tabular}{|l|l|}
\hline Axial Length & No. of Eyes \\
\hline 22.01 TO 24.00 & 26 \\
\hline 24.01 TO 26.00 & 49 \\
\hline 26.01 TO 28.00 & 88 \\
\hline 28.00 TO 30.00 & 23 \\
\hline 30.01 TO 32.00 & 14 \\
\hline
\end{tabular}

The highest axial length of the eye ball in this study was $31.74 \mathrm{~mm}$, but the majority of the cases showed axial length in between $24.01 \mathrm{~mm}$ to $28.01 \mathrm{~mm}$ [Table-1].

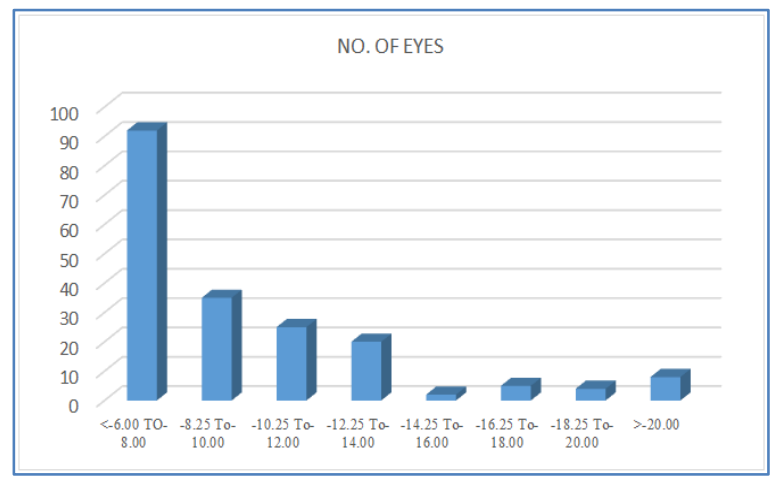

Fig-3: Spectacle Power 
Table-2: posterior segment abnormalities in high and pathological myopia $(\mathrm{N}=100)$

\begin{tabular}{|c|c|c|}
\hline $\begin{array}{c}\text { Posterior Segment } \\
\text { Changes }\end{array}$ & $\begin{array}{c}\text { No. of } \\
\text { Cases }\end{array}$ & $\begin{array}{c}\text { No. of Eyes } \\
\text { Affected }\end{array}$ \\
\hline Vitreous degeneration & 57 & 78 \\
\hline Myopic crescent & 57 & 103 \\
\hline $\begin{array}{c}\text { Chorioretinal } \\
\text { degeneration }\end{array}$ & 38 & 69 \\
\hline Lattice degeneration & 25 & 30 \\
\hline $\begin{array}{c}\text { Posterior vitreous } \\
\text { detachment }\end{array}$ & 5 & 6 \\
\hline Posterior staphyloma & 8 & 12 \\
\hline Lacquer cracks & 7 & 11 \\
\hline Foster Fuchs spots & 11 & 12 \\
\hline $\begin{array}{c}\text { Paving stone } \\
\text { degeneration }\end{array}$ & 8 & 9 \\
\hline White without pressure & 13 & 15 \\
\hline Retinal holes & 8 & 8 \\
\hline Retinal tears & 2 & 2 \\
\hline Retinal detachment & 2 & 2 \\
\hline
\end{tabular}

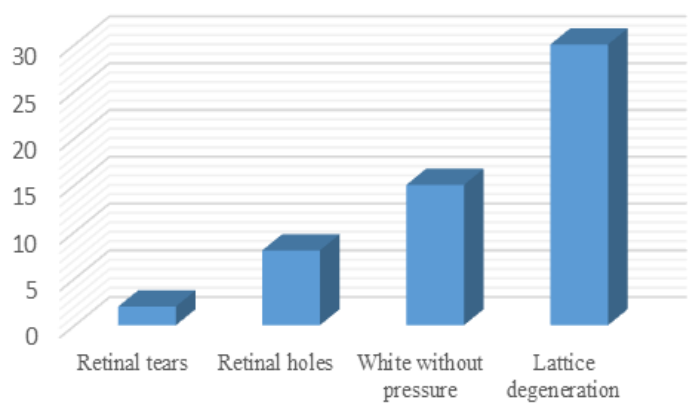

Fig-4: Lesion's predisposing to Retinal Detachment

The maximum axial length of the eyeball recorded in the study is $31.74 \mathrm{~mm}$ in a phakic eye with 25.00 Dsph. Unilateral high myopia was seen in 4 eyes $(2 \%)$. Amblyopia seen in 14 eyes with high myopia. 2cases (4 eyes) of the micro cornea with high myopia were observed. Myopic crescent observed in 103 eyes with high myopia and pathological myopia. Vitreous detachment observed in 6 eyes with high myopia. Posterior staphyloma seen in 12 eyes with pathological myopia. Foster Fuch spots noted in 12 eyes with pathological myopia. Good vision is seen in 58 eyes, a medium vision seen in 72 eyes and poor vision seen in 66 eyes with high myopia. 2cases (4 eyes) of Retinitis Pigmentosa with high myopia were seen. Lattice degeneration is seen in 30 Eyes. Lacquer cracks observed in 7 cases (11 Eyes) with pathological myopia. White without pressure is seen in 15 Eyes with high myopia. Paving Stone degeneration is observed in 9 Eyes. Chorioretinal degeneration is seen in 69 eyes with high myopia. Myopic CNV is seen in 2 eyes with high myopia. Retinal detachment is observed in 2 eyes with pathological myopia with peripheral retinal degeneration [Table 2 \& Figure 3, 4].

\section{DISCUSSION}

The High myopia or pathological myopia is associated with globe elongation and a refractive error of at least six diopters (D) and axial length of greater than $25.5 \mathrm{~mm}$. Excessive axial elongation of the globe in high myopia can cause mechanical stretching and thinning of the choroid and retinal pigment epithelium layers, resulting in various retinal degenerative changes. The peripheral retina is prone for various degenerations secondary to its anatomical dehiscences like thinness, presence of poorly developed retinal cells and absence of large blood vessels etc. Its less resistance to traction in the presence of degeneration makes it vulnerable to retinal detachment. In a crosssectional community-based epidemiological study in Hong Kong, $56.1 \%$ and $11.3 \%$ of subjects with high myopia were found to have one or more peripheral retinal degenerative lesion or posterior pole lesion respectively. The studies done by Rosenthal and Von Noorden showed that in cases of unilateral high/pathological myopia involvement of the right eye is more common. In the present study, unilateral high myopia is found in the right eye in 4 cases. In this study 2 cases (4 eyes) of microcornea have been reported in association with high and pathological myopia. This correlates with the studies of Fahim F in 1934, Brio E in 1935, Fuch A in 1937, Batra DV and Paul SDwho reported high and pathological myopia in association with micro cornea. In the present study maximum axial length of the eyeball recorded is $31.74 \mathrm{~mm}$ in the phakic eye with -25.00 Dsph of myopia. An axial length of more than $30.00 \mathrm{~mm}$ is seen in 14 eyes with myopia ranging from 20.00 to $25.00 \mathrm{Dsph}$. In the present study, amblyopia is seen in 9 cases (14 eyes) with high and pathological myopia. In 8 eyes, the severity of amblyopia corresponded to the amount of myopia Vitreous floaters were seen in $36 \%$ of eyes which is due to vitreous degeneration in myopes. In the present study, degenerative changes in vitreous are observed in 57 cases (78 eyes) with high and pathological myopia (39.7\% incidence). In the present study, temporal crescents were the most commonly seen. There was also shallow cupping of the disc. These changes were probably due to elongation of the globe. In few cases, macula showed stippled appearance due to thinning of the retina. In the present study, Chorioretinal degeneration is noticed in 69 eyes with high and pathological myopia. The association of Chorioretinal degeneration with high myopia is increasingly seen with increasing axial length and myopic power of the eye ball. This finding correlates with a study conducted by Curtin BJ \& Karlin DB in 1971. In the present study, ten eyes are found $(5.1 \%$ incidence) with high and pathological myopia. This correlates with a study conducted by Karaman K et al. [1, 2, 4, 3]. Lacquer cracks are spontaneous ruptures in the Bruch's membrane predisposing patients with high myopia to develop sudden visual loss as macular choroidal neovascularisation may develop near the lacquer cracks. Small ingrowth of fibro vascular tissue may also give 
rise to small elevated pigmented circular lesions and are known as Fuchs' spots. In this study, lacquer cracks are seen in 7 cases (11 eyes, 5.6\% incidence) with an axial length of $26.50 \mathrm{~mm}$ and more with high myopia. Among the different types of peripheral retinal degenerations in high myopia, lattice degeneration is the most important peripheral retinal degeneration which can predispose to rhegmatogenous retinal detachment. Lattice degeneration is more commonly seen in the superior-temporal quadrant. This is probably due to excessive stretching and increased vascularity of this area. On the edge of lattice, vitreous adhesion (43) is commonly seen, and this accounts for the association of retinal detachment with lattice degeneration (44). A study was done by Jose. M. Celorio et al. [4, 6] showed that out of 218 patients with myopia of $6 \mathrm{D}$ or more, 72 [33\%] had lattice degeneration. In the present study, lattice degeneration is seen in 30 eyes. Increasing prevalence of lattice is seen in persons with an increase in axial length of the eye ball, and it is more frequently seen in temporal half of retina. It was reported by $\mathrm{O}$ Malley PF et al. [4, 5, 8, 9] that paving stone degeneration is present in $22 \%$ of adult patients and is bilateral in $38 \%$ of them and prevalence increases markedly with increased age. In the present study, it is seen in 9 eyes $(4.5 \%)$ with pathologic myopia. It is seen in eyes with an axial length of more than $25 \mathrm{~mm}$. As per the study conducted by Manoj Shukla et al. [4, 7, 1012] on white with pressure and white without pressure lesions, white with pressure was seen in $27.6 \%$ of myopic eyes. In the present study white without pressure areas are seen in 15 eyes $(7.6 \%)$ with high and pathological myopia. It is observed in the inferior temporal quadrant. It is seen in areas of lattice degeneration and about small retinal breaks. In the present study, two eyes with retinal detachment, four eyes with retinitis pigmentosa, 12 eyes ( 8 cases) with posterior staphyloma, and two eyes with choroidal neovascularization have been reported in association with high and pathological myopia.

\section{CONCLUSION}

A study of 100 cases of myopia was done. The majority of cases of myopia were observed in the age group of the third decade. By gender, the male preponderance is seen in the distribution of high myopia. Fundal changes in myopia were observed to increase as the degree of refractive error increased. Temporal crescent was the commonest type of myopic crescent observed. It is well documented that myopes, especially high and pathological myopes, tend to suffer from compromised quality of life owing to various influences from functional, psychological, cosmetic, and financial factors. Individuals with high myopia were reported to have a significantly lower visionrelated quality of life than those with none, mild, or moderate myopes. All cases have to be examined with due importance to dilated fundus examination so that timely care is given and to enhance the quality of life of such patients.

\section{REFERENCES}

1. Brian $\mathbf{J}$ and Curtin M.D: The Myopias - basic science \& clinical management, Harper \& Row Publishers, Philadelphia, 1985.

2. Support for Vision Research, Washington, DC, Department of Health, Education \& Welfare Publication No. (NIM) 1976; 76-1098.

3. Brasil OF, Brasil MV, Japiassu RM, Biancardi AL, Souza DD, Oliveira RC. Fundus changes evaluation in degenerative myopia. Arq Bras Oftalmol. 2006; 69(2):203-6.

4. Pan CW, Dirani M, Cheng CY, Wong TY, Saw SM. The age-specific prevalence of myopia in Asia: a meta-analysis. Optom Vis Sci. 2015; 92(3):258-66.

5. He M, Zeng J, Liu Y, Xu J, Pokharel GP, Ellwein LB. Refractive error and visual impairment in urban children in southern China. Invest Ophthalmol Vis Sci. 2004; 45(3):793-9.

6. Congdon N, Wang Y, Song Y, Choi K, Zhang M, Zhou Z, et al. Visual disability, visual function, and myopia among rural Chinese secondary school children: the Xichang Pediatric Refractive Error Study (X-PRES)--report 1. Invest Ophthalmol Vis Sci. 2008; 49(7):2888-94.

7. Morgan IG, Ohno-Matsui K, Saw SM. Myopia. Lancet. 2012; 379(9827):1739-48.

8. Saw SM, Gazzard G, Shih-Yen EC, and Chua WH. Myopia and associated pathological complications. Ophthalmic Physiol Opt. 2005; 25(5):381-91.

9. Xu L, Wang Y, Wang S, Wang Y, Jonas JB. High myopia and glaucoma susceptibility the Beijing Eye Study. Ophthalmology. 2007; 114(2):216-20.

10. Morgan I, Rose K. How genetic is school myopia? Prog Retin Eye Res. 2005; 24(1):1-38

11. Lin LL, Shih YF, Hsiao CK, Chen CJ. Prevalence of myopia in Taiwanese schoolchildren: 1983 to 2000. Ann Acad Med Singapore. 2004; 33(1):2733.

12. Karlin DB, Curtin BJ. Peripheral chorioretinal lesions and axial length of the myopic eye. Am J Ophthalmol. 1976; 81(5):625-35. 